\title{
Morphological and Molecular Identification of Ticks Infested in Stray Dogs within Nay Pyi Taw Area, Myanmar
}

\author{
Myint Myint Huoon ${ }^{1}$, Lat Lat Htun ${ }^{1}$, Soe Soe WaI ${ }^{2}$, May June Thu ${ }^{3}$, Si Thu Aung $^{1}$, Hla Myet \\ CheL $^{1,3}$, Yu Nandi Thaw ${ }^{1}$, Shwe Yee Win ${ }^{1}$, Nyein Chan SoE ${ }^{1}$, Saw Bawm ${ }^{1 *}$
}

${ }^{1}$ Department of Pharmacology and Parasitology, University of Veterinary Science, Nay Pyi Taw 15013, Myanmar; ${ }^{2}$ Department of Veterinary Public Health, University of Veterinary Science, Nay Pyi Taw 15013, Myanmar; ${ }^{3}$ Laboratory of Parasitology, Department of Disease Control, Graduate School of Veterinary Medicine, Hokkaido University, Japan.

\begin{abstract}
Rhipicephalus sanguineus, the brown dog tick, is the most widespread tick in the world and transmits broad range of pathogens to dogs. The aim of this study was to identify the tick species infested in dogs by using a combination of LM and molecular analysis. A total of 237 tick samples were collected from dogs and identified by using Light Microscope (LM) and molecular technique. Morphological identification revealed that all of tick infestation in dogs was $R$. sanguineus spp. and 16SrRNA gene of $R$. sanguineus species sequences analyses proved $100 \%$ sequences identitieswhen compared with the reference data in Genbank records. The present studies confirm $R$. sanguineus is common tick species infesting in dogs within Nay Pyi Taw area.
\end{abstract}

Keywords | Cured pigment, Lactic acid bacteria, Metmyoglobin, Probiotic, Sausage.

\author{
Editor | Muhammad Nauman Zahid, Quality Operations Laboratory, University of Veterinary and Animal Sciences, Lahore, Pakistan. \\ Received | July 27, 2018 Accepted | August 12, 2018; Published | September 05, 2018 \\ *Correspondence | Saw Bawm, Department of Pharmacology and Parasitology, University of Veterinary Science, Nay Pyi Taw 15013, Myanmar; Email: best- \\ shadow@gmail.com \\ Citation | Hmoon MM, Htun LL, Wai SS, Thu MK, Aung ST, Chel HM, Thaw YN, Win SY, Soe NC, Bawm S (2018). Morphological and Molecular Identi- \\ fication of Ticks Infested in Stray Dogs within Nay Pyi Taw Area, Myanmar. S. Asian J. Life Sci. 6(2): 41-45. \\ DOI | http://dx.doi.org/10.17582/journal.sajls/2018/6.2.41.45 \\ ISSN | 2311-0589
}

Copyright (c) 2018 Hmoon et al. This is an open access article distributed under the Creative Commons Attribution License, which permits unrestricted use, distribution, and reproduction in any medium, provided the original work is properly cited.

\section{INTRODUCTION}

$\mathrm{W}$ orldwide, there is a growing recognition of the importance of tick-borne pathogens in dogs and humans, whichare transmitted by a number of different ixodid tick species (Nicholson et al., 2010). Rhipicephalus sanguineus, the brown dog tick, is the most widespread tick in the world and is a well-recognized vector of tick-borne pathogens affecting dogs and occasionally humans (Dantas-Torres, 2016). Rhipicephalus sanguineus transmits broad rangeof pathogens to dogs such as Babesia vogeli, Babesia gibsoni, Hepatozoon canis, Rickettsia conorii, Rickettsia rickettsii, Ehrlichia canis and Anaplasma platys (Jongejan and Uilenberg, 2004; Beugnet and Marie, 2009).

The accurate taxonomy of tick species is a very important to control tick-borne diseases. The morphological identification using light microscope (LM) clarifies mainly the size and color of tick species besides other obvious charac- teristics such as mouth parts, the outline of body and scutum (Abdel-Shafy, 2008). Traditionally, taxonomical identification of ticks was based on the criteria of adult ticks through LM or SEM, nonetheless, the applicability of this method is difficult when the specimens are engorged with blood, physically damaged, in immature stages; i.e. eggs, larvae, or nymphs (Caporale et al., 1995; Guglielmone et al., 2006) and very doubtful at subspecies and/or one group level; $R$. sanguineus group (Gray et al., 2013; Luiet al., 2013; Nava et al., 2015).

The number of pet dogs is increasing in Myanmarwhile the numbers of infected stray dogs are roaming at streets, fresh open markets, and other public places in Myanmar's urban areas. As in many other countries, thedog has become a bonded family member. Among canine diseases, the zoonotic diseases are of significant importancein public health (Day, 2011; Irwin, 2014). Ticks are one of the most common ecto parasites in dogs and are involved in the 
transmission of a number of major diseases in both dogs and humans (Chomel, 2011; Dantas-Torres and Otranto, 2016). Along with the changes of climate and environmentalecosystem, increasing emerging and re-emerging tick-borne diseases and therefore ticks have been considered as the focus of extensive attention in recent years (Jongejan and Uilenberg, 2004; Liu et al., 2014). The increase in the pet dogpopulation and their close relationship with humans inMyanmar has created the need for research into the epidemiological status of ticks and the pathogens they transmit to pet dogs. However, there is very little information on morphological and genetically identification of ticks in Myanmar. Therefore, the aim of this study was to determine the morphological and molecular identification of tick species infested in stray dogs within Nay Pyi Taw area, Myanmar.

\section{MATERIALS AND METHODS}

\section{Collection of Tick Samples}

A total of 400 dogs were investigated for tick infestation. The inspected dogs were from Pyinmana, Lewe, Tatkon and Zeyar Thiri Township within Nay Pyi Taw area. These animals were examined for the presence of ticksin neck, chest area, and around the soft parts of theirbodies such as the inner sides of the hind and forelegs,perineal area, inner surface of ears and udders (Abdullah et al., 2016). Dogs were examined whether the ticks were present or not, andif present,ticks were collected by hand from the dogs. Nomore than 10 ticks were collected from each dog and placed in a collection tube containing a wet cotton ball. Each sample was registered and numbered.

\section{Morphological IdenTification of Tick Vectors BY LM}

In accordance with the morphology of ticks, an observation was performed microscopically to determine their developmental stage (larval, nymph, adult) andspecies. Ticks were identified using recognized morphological keys (Parola et al., 2013). The collected ticks were counted and sorted to different, species, and sex using dissecting microscope. Tick species were identified morphologically using taxonomic keys of Estrada-Pena et al. (2004). The identification of tick species were morphologically examined in details using LM, especially the dorsal and ventral surfaces of adult males and females. The adult ticks in these two positions were photographed by digital camera fixed on stereo microscope.

\section{Extraction of Tick DNA}

Before the extraction procedure, individual ticks were disinfected by immersion into $70 \%$ ethanol for $5 \mathrm{~min}$, rinsed in sterile water and dried with sterile filter paper. Tick samples were homogenized by Micro Smash MS-
100R homogenizer (TOMY MEDI Co., Ltd., Japan) and then theywere subjected to DNA extraction using the $\mathrm{DNAZol}^{\oplus}$ (genomic DNA isolation reagent) (Molecular Research Center, USA) in accordance with the manufacturer's instructions. DNA was eluted in a final volume of $200 \mu \mathrm{l}$ and kept at $-20^{\circ} \mathrm{C}$ until tested by polymerase chain reaction (PCR).

\section{PCR Amplification of Target Sequences}

The amplification reactions were performed in $25 \mu \mathrm{l}$ total volumes under complete aseptic conditions. Each PCR mixture contained $1 \mu \mathrm{l}$ of genomic DNA, $0.5 \mu$ lof $(10 \mu \mathrm{M})$ forward and reverse primers, $12.5 \mu 1$ of $\times 2$ Gflex PCR buffer (Mg2+, dNTP plus) (TAKARA BIO INC., Japan), 0.5 $\mu 1$ of Tks Gflex DNA polymerase (TAKARA BIO INC., Japan), and $10 \mu 1$ nuclease free water (Qiagen) to completethe total volume of the reactions. PCR amplification for 16S rRNA gene fragment was done as previously described (Ushijima et al., 2003). The primers were used Mt-rrs 1 (CTGCTCAATGATTTTTTAAATTGCTGTGG) and Mt-rrs2 (CCGGTCTGAACTCAGATCAAGTA) for the product (401-416 bp).PCR amplifications was performed in a Simpli Ampthermal cycler (Applied Biosystem, USA) utilizing the following cycling profile; one cycle at $94^{\circ} \mathrm{C}$ for $1 \mathrm{~min}$ (initial denaturation). The PCR protocol of $16 \mathrm{~S}$ rDNA was amplified according to the following: 40 cycles denaturation at $94^{\circ} \mathrm{C}$ for $1 \mathrm{~min}$, annealing at $55^{\circ} \mathrm{C}$ for $30 \mathrm{sec}$ andelongation at $68^{\circ} \mathrm{C}$ for $30 \mathrm{sec}$, and the final elongation at $68^{\circ} \mathrm{C}$ for $5 \mathrm{~min}$. The $\mathrm{PCR}$ products were visualized by electrophoresis on $1.5 \%$ agarose gels stained with RedSafe $^{\mathrm{TM}}$ (INtRON Biotechnology, USA).

\section{Sequence and Phylogenetic Analysis}

Randomly selected positive PCR products were purified using the NucleoSpin ${ }^{\circledR}$ and PCR Clean-up Kit (MACHEREY-NAGEL, Düren, Germany) according to the manufacturer's instructions. Purified PCR products were sequenced with ABI 3130 genetic analyzer (Model 3130; Applied Biosystems, Foster City, CA, USA) with forward and reverse primers. Nucleotide sequences were compared with GenBank entries using NCBI BLAST.Multiple sequence alignments of amplicons and $16 \mathrm{~S}$ rRNA sequences from GenBank were performed using the ClustalW Version 1.8 (Thompson et al., 1994). Phylogenetic trees were inferred using neighbor-joining (NJ) analysis by MEGA software Version 7.0 (Kumar et al., 2016). The distance matrix of nucleotide divergences was calculated according to Kimura's two-parameter model furnished by MEGA. A bootstrap resampling technique of 1000 replications was performed to statistically support the reliabilities of the nodes on the trees. 


\section{RESULTS AND DISCUSSION}

\section{Morphological and Molecular Identification of Tick Species}

A total of 237 ticks were collected from 44 dogs during this investigation. All ticks were collected from four Townships within Nay Pyi Taw area. The ticks collected were of the three development stages i.e., larval, nymphal and adult ticks, where adults, nymphs and larvae counted for (217/237) 91.6\%, (20/237) 8.4\% and (0/237) 0\%, respectively.All stages were identified and the species identified were Rhipicephalus sanguineus (237/237). The key characteristics of adult female and male of the brown dog tick, $R$. sanguineus are as described by Walker et al. (2014). Interstitial punctation size is small to medium. Interstitial punctation distribution is sparse. Coxae 1 anterior spurs are not visible dorsally. Cervical field depression is not apparent. Cervical field texture has no wrinkles. Eyes are slightly convex. Genital aperture posterior lips have a broad U shape (but may have a broad V shape). Conscutum colour is pale (but may be dark in some populations). Accessory adanal plates are large. Adanal plates shape is narrow and trapezoid (but tends towards a broad and curved appearance). Posterior grooves are distinct (deep and wide with wrinkled texture) (Figure 1).

\section{Morphological characteristic of $\boldsymbol{R}$. sanguineus}
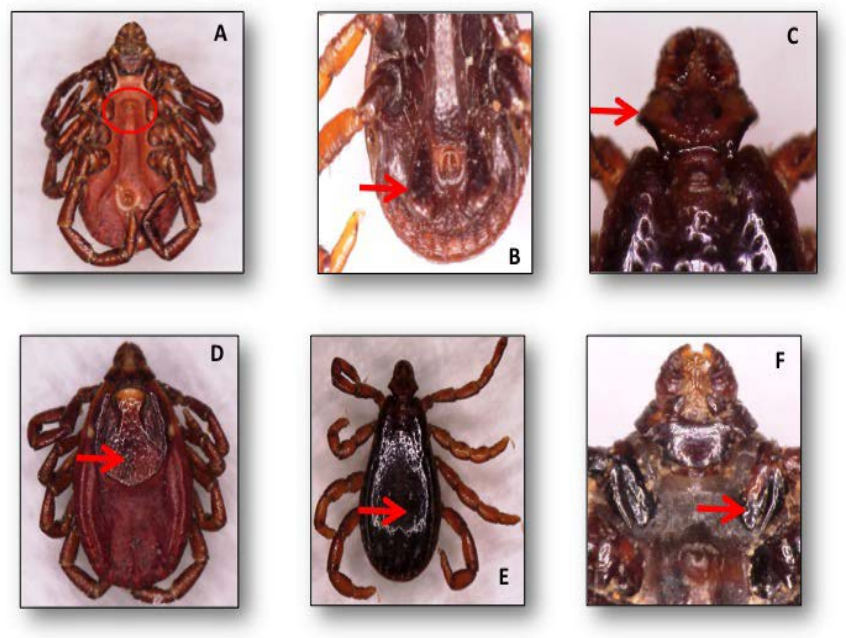

Figure 1: The adult female and male of the brown dog ticks Rhipicephalus sanguineus photographed by light microscope: (A) genital opening of $R$. sanguineus (Female); (B) adanal plate of $R$. sanguineus (Male); (C) hexagonal shape of basic capiculi; (D) dorsal view of $R$. sanguineus (Female scutum); (E) dorsal view of $R$. sanguineus (Male conscutum); (F)divided $1^{\text {st }}$ coxa of $R$. sanguineus.

The sequences obtained (accession no. LC422405) was compared by using BLAST (www.ncbi.nlm.nih.gov/blast) with sequences available at GenBank. Sequences obtained were similar to that of $R$. sanguineus reported from Bra- zil, Chile, Cuba, Thailand and China (GenBank accession no. KR653223, KX632154, KP830114, KC170744 and DQ093297) with similarities of $100 \%$ (Figure 2).

Phylogenetic tree of $R$. sanguineus Tick species

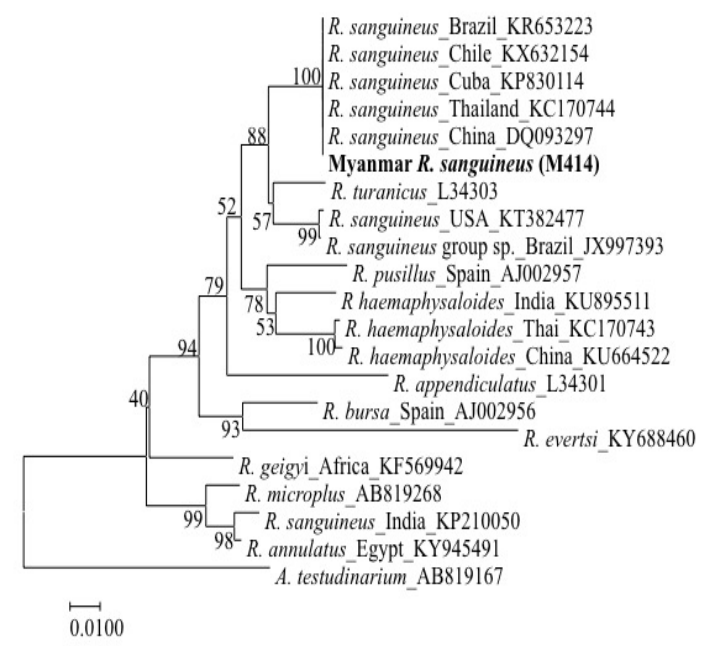

Figure 2: Phylogenetic tree based on $R$. sanguineus spp. $16 \mathrm{~S}$ rDNA sequence. Sequences from the Rhipicephalus genera were compared with the neighbor-joining method with distance matrix calculation by Kumar-two parameters, operated by MEGA software (Version 7), using Amblyomma testudinarium as the out group. Scale bar indicates the number of mutations per sequence position. The numbers at the nodes represent the percentage of 1000 bootstrap re-samplings.

Nowadays, the contact between wild and domestic animals, animals and human aswell as animals, human and vectors are increasing (Wieten et al., 2011; Gargili et al., 2012; Keysary et al., 2011; Socolovschi et al, 2011; Movila et al., 2012). In addition, the studies on emerging and reemerging infectious diseases are also increasing due to their public health implication, zoonotic importance. Therefore, the accurate taxonomy of tick is a very important to control tick-borne diseases. Molecular techniques are needed to improve the sensitivity and specificity of the identification of tick species. Therefore, this study was designed to achieve two goals. The firstgoal is to determine the ixodid tick species infesting dogs by LM. The second goal is to illustrate the accurate taxonomic status of the most common ticks, the brown $\operatorname{dog}$ tick $R$. sanguineus, using a molecular analysis.

The brown $\operatorname{dog}$ tick $R$. sanguineus is the unique tick species that was found on dogs recording $100 \%$ infestation (Hoogstraal and Kaiser, 1958; Haridy et al., 2009). Many tick species have been identified on dogs in SEA, but the brown dog tick, $R$. sanguineus, is the most significant in terms of its prevalence (Tanskul et al. 1983; Kolonin, 1995; Petney and Keirans, 1996). The findings of this study reveal 
the fact that $R$. sanguineus is still the main dog tick in $\mathrm{My}-$ anmar which agrees with previous reports.

\section{CONCLUSIONS}

Rhipicephalus sanguineus is of great significance in both veterinary andhuman medicine, primarily because of its role as a vector of several pathogens, though the ticks themselves can cause clinical illnessin heavy infestations of dogs. The present studies proved that $R$. sanguineus is common tick species infesting in dogs around Nay Pyi Taw area. In addition, the establishment of the phylogenetic status of $R$. sanguineus would be useful in understanding the distribution of ticks in Nay Pyi Taw area.

\section{ACKNOWLEDGEMENTS}

This research was supported by Laboratory of Parasitology, Graduate School of Veterinary Medicine, Hokkaido University, Japan. The authors are grateful to Prof. Dr. Ken Katakura and Associate Prof. Dr. Ryo Nakao, Laboratory of Parasitology, Graduate School of Veterinary Medicine, Hokkaido University, Japan their supporting and cooperation.

\section{CONFLICT OF INTEREST}

The authors declare that they have no conflicts of interest.

\section{AUTHORS' CONTRIBUTION}

All authors contributed equally in research and writing of manuscript.

\section{REFERENCES}

- Abdel-Shafy S (2008). Scanning electron microscopy and comparative morphology of Hyalomma anatolicum excavatum, $H$. dromedarii and $H$. marginatum marginatum (Acari: Ixodidae) based on nymphs. Acarologiya. 48: 3-18.

- Abdullah S, Helps C, Tasker S, Newbury H,Wall R (2016). Ticks infesting domestic dogs in the UK: A large scale surveillance programme. Parasit. Vectors. 9: 391. https://doi. org/10.1186/s13071-016-1673-4

- Beugnet F, Marie J (2009). Emerging arthropod-borne diseases of companion animals in Europe. Veterinary Parasitology. 163: 298-305.

- Caporale DA, Rich SM, Spielman A, Telford SR, Kocher TD (1995). Discriminating between Ixodes ticks by means of mitochondrial DNA sequences. Mol. Phylogenet. Evol. 4: 361-365. https://doi.org/10.1006/mpev.1995.1033

- Chomel B (2011). Tick-borne infections in dogs:Anemerging infectious threat. Vet. Parasitol. 179: 294-301. https://doi. org/10.1016/j.vetpar.2011.03.040

- Dantas-Torres F,Otranto D(2016). Best practices forpreventing vector-borne diseases in dogs and humans. Trends Parasitol.
32: 43-55. https://doi.org/10.1016/j.pt.2015.09.004

- Day MJ (2011). One health: the importance of companion animal vector-borne diseases. Parasit. Vectors. 4: 49. https:// doi.org/10.1371/journal.pone.0021965

- Estrada-Pena A, Bouattour A, Camicas JL, Walker AR (2004). Ticks of Domestic Animals in the Mediterranean Region: A Guide to Identification of Species. Zaragoza: University of Zaragoza.

- Gargili A, Palomar AM, Midilli K, Portillo A, Kar S, Oteo AJ (2012). Rickettsia species in ticks removed from humans in Istanbul, Turkey. Vector Borne Zoonotic Dis. 12: 938-941. https://doi.org/10.1089/vbz.2012.0996

- Gray J, Dantas-Torres F, Estrada-Pena A, Levin M (2013). Systematics and ecology of the brown dog tick, Rhipicephalus sanguineus. Ticks \&Tick Borne Dis.3: 171-180. https://doi. org/10.1016/j.ttbdis.2012.12.003

- Guglielmone AA, Venzal JM, Gonzáleh Z, Acuña D, Nava S, Hinojosa A,Mangold AJ (2006). The phylogenetic position of Ixodes stilesi Neumann 1911 (Acari:Ixodidae): Morphological and preliminary molecular evidences from 16S rDNA sequences. Syst. Parasitol. 65: 1-11. https://doi. org/10.1007/s11230-005-9024-4

- Haridy FM, Hassan AA, Hafez AO, El-Sherbini GT, Morsy TA (2009). External and intestinal parasites ofpet dogs with reference to zoonotic toxocariasis. J. Egypt. Soc. Parasitol. 39: 321-326.

- Hoogstraal H, Kaiser MN (1958). The ticks (Ixodoidea) of Egypt: A brief review and keys. J. Egypt Public Health Assoc. 33: 51-85.

- Irwin PJ (2014). It shouldn't happen to a dog or a veterinarian: clinical paradigms for canine vector-borne diseases. Trends Parasitol. 30: 104-112. https://doi.org/10.1016/j. pt.2013.12.001

- Jongejan F, Uilenberg G (2004). The global importance of ticks. Parasitology.129, S3-S14. https://doi.org/10.1017/ S0031182004005967

- Keysary A, Eremeeva ME, Leitner M, Din AB, Wikswo EM, Mumcuoglu YK, Inbar M, Wallach DA,Shanas U, King R, Waner T (2011). Spotted fever group rickettsiae in ticks collected from wild animals in Israel. Am. J. Trop. Med. Hyg. 85: 919-923. https://doi.org/10.4269/ajtmh.2011.10-0623

- Kolonin GV (1995). Review of the Ixodid tick fauna (Acari: Ixodidae) of Vietnam. J. Med. Entomol. 32: 276-282. https://doi.org/10.1093/jmedent/32.3.276

- Kumar S, Stecher G, Tamura K (2016). MEGA7: Molecular Evolutionary Genetics Analysis Version 7.0 for Bigger Datasets. Mol Biol Evol. 33:1870-1874.

- Liu Q, He B, Huang SY, Wei F, Zhu XQ (2014). Severe feverwith thrombocytopenia syndrome, an emerging tickborne zoonosis. Lancet Infect. Dis. 14: 763-772. https://doi. org/10.1016/S1473-3099(14)70718-2

- Lui GH, Chen YZ, Song HQ, Lin RQ, Zhou DH, Zhu XQ (2013). Complete mitochondrial genome sequance data provides evidence that dog tick Rhipicephalus sanguineus (Acari: Ixodidae) represents a species complex. Int. J. Biol. Sci. 9: 361-369. https://doi.org/10.7150/ijbs.6081

- Movila A, Alekseev AN, Dubinina HV, Toderas I (2012). Detection of tick-borne pathogens in ticks from migratory birds in the Baltic region of Russia. Med. Vet. Entomol. 27: 113-117. https://doi.org/10.1111/j.13652915.2012.01037.x

- Nava S, Estrada-Pena A, Petney T, Beati L, Labruna BM, Szabo PJM, Venzal MJ, Mastropaolo M, Mangold 
JA, Guglielmone AA (2015). The taxonomic status of Rhipicephalus sanguineus (Latreille, 1806).Vet. Parasitol. 208: 2-8. https://doi.org/10.1016/j.vetpar.2014.12.021

- Nicholson WN, Allen KE, McQuiston JH, Breitschwerdt EB, Little SE (2010). The increasing recognition of rickettsial pathogens in dogs and people. Trends Parasitol. 26: 205-212.

- Parola P, Paddock DC, Socolovschi C, Labruna BM, Mediannikov O, Kernif T, Abdad YM, Stenos J, Bitam I, Fournier P, Raoult D (2013). Update ontick-borne Rickettsioses around the world: A geographic approach. Clin. Microbiol. Rev. 26: 657-702. https://doi.org/10.1128/ CMR.00032-13

- Petney TN, Keirans JE (1996). Ticks of the genera Boophilus, Dermacentor, Nosomma and Rhiphicephalus (Acari: Ixodidae) in South East Asia. Tro. Biomed. 13: 73-84.

- Socolovschi C, Reynaud P, Raoult D, Parola P (2011). Rickettsiae and Borrelia in ticks on migratory birds from the Camargue National Park, France. In: Abstract Book of the $6^{\text {th }}$ International Meeting on Rickettsiae and Rickettsial

Diseases. Heraklion, Crete, Greece. P-114.

- Tanskul P (1983). A checklist of Ticks in Thailand (Acari: Metastigmata: Ixodidadia). J. Med. Entomol. 20: 330-341. https://doi.org/10.1093/jmedent/20.3.330

- Thompson JD, Higgins DG, Gibson TJ (1994). CLUSTAL $\mathrm{W}$ : improving the sensitivity of progressive multiple sequence alignment through sequence weighting, positionspecific gap penalties and weight matrix choice. Nucleic Acids Res. 22: 4673-4680.

- Walker JB, Keirans JE, Horak IG (2000). Genus Rhipicephalus (Acari, Ixodidae). A guide to the brown ticks of the world. Cambridge: Cambridge University Press; Cambridge, UK. 656.

- Wieten RW, Hovius JW, Groen EJ, van der Wal AC, de Vries PJ, Beersma MF, Tijsse-Klasen E, Sprong H, Grobusch MP (2011). Molecular diagnostics of RickettsiaAfricae infection in travelers returning from SouthAfrica to The Netherlands. Vector Borne Zoonotic Dis.11: 1541-1547. https://doi. org/10.1089/vbz.2011.0653 